\title{
Diagnosis of Phlebotomas Argentipes as a Vector for Visceral Leismaniasis by PCR in Bangladesh.
}

\author{
Chowdhury M Z1 , Haq J U A², Huq F³, Shamsuzzaman SMA ${ }^{4}$, Shamsuzzam SM5.
}

Abstract:

Objectives: The present study was undertaken to diagnose sandfly as a vector of visceral leismaniasis by PCR in Bangladesh.

Place and period of study: The study was conducted in Fulbaria Upazilla of Mymensing District during 2001-2004.

Materials \& Methods: The study was conducted in the department of Microbiology, National Institude of Preventive and social medicine (NIPSOM), Mohakhali, Dhaka. DNA extraction from Sand Fly: All the procedure followed for DNA extraction from Bone marrow is same for sandfly except $A L$ buffer where instead of $A L$ buffer $A T L$ buffer were added. The primers used are constructed from KDNA of $L$. (L) donovani. DD8 strain to amplify a fragment of 354 bp in length.

Results: PCR of extracted DNA from sandfly (P.argentipes) revealed 354 bp bands similar to buffy coat and bone mamow samples containing DNA of L. Donovani. This might be the first demonstration of L.donovani parasite in sand fly vector in Bangladesh.

Conclusion: The present study shows that PCR is a good diagnostic tool for the demonstration of L.donovani parasite for the P.argentips sp in Bangladesh.

Key words:P.argentipes, V.Leishmaniasis, PCR, Sandfly

1. Md. Zaforullah Chowdhury, Professor of Microbiology, East West Medical College (EWMC).

2. Jalal Uddin Asharful Haq, Professor of Microbiology, IBMC.

3. Farida Huq, Professor of Microbiology, BIRDEM.

4. SMA Shamsuzzaman, Associate Professor of Microbiology, DMC.

5. SM Shamsuzzaman, Professor of Microbiology, IEDCR.

Correspondence : Md. Zaforullah Chowdhury, Professor of Microbiology, EWMC. 


\section{Introduction}

Kala-azar has appeared to be a serious health problem of the developing countries including Bangladesh. Available records indicate the presence of this disease in endemic form in Bangladesh as early as fifth decade of the nineteenth century ${ }^{1}$. But during 1960s, the disease almost disappeared due to malaria eradiction activities. A resurgence of KA was first noted in early 1970 when 59 parasitologically confirmed cases were reported from different parts of Bangladesh ${ }^{2}$. A study in late eighties reported the incidence of KA as up to 9 cases/ 1000 population in the endemic areas of Bangladesh and 31 out of 64 district are already affected ${ }^{3}$. Early diagnosis of KA is necessary to reduce morbidity and mortality. The conventional diagnosis of KA is mainly based on demonstration of parasities in biopsies or aspirates of spleen, bone marrow and lymph nodes Recently polymerease chain reaction (PCR) has been successfully used to diagnose KA cases from the bone marrow, lymph nodes aspirates and blood ${ }^{4,5}$. In Bangladesh and other countries, several studies have compared different diagnostic tools for the diagnosis of L. donovani infection and found IFAT, ELISA \& DAT equally sensitive and specific $^{6}$. ELISA was positive in $100 \%$ parasitologically positive KA cases and negative in the control group. Similar finding was also reported by Muassam et al in (1990)7. Therefore, we are interested to investigate the use of ELISA for the diagnosis of visceral leishmaniasis $\lg G$ and IgG subclass as a diagnostic marker ${ }^{7}$.

Two species of Phlebotamus, P.argentipes and P.papatasi and five species of Sergentomyia, S. babu babu, S. Baghdadis, S. shorttii, S. barraudi and a new species were identified from fixed localities in Dhaka and Rajshahi division of Bangladesh. Some studies were tried to detect L.donovani parasite in the sand fly by dissection but failed and so far no studies could demonstrate the presence of parasite in these vector in Bangladesh. The detection of Leishmania donovani DNA in sand flies caught in Bangladeshi KA patients' dwellings was also studied using PCR (Mukherjee et al., 1997). Therefore, we are interested to investigate the utility of PCR in the detection of parasite in sand flies caught in KA patient dwellings of the endemic localites by PCR method.

\section{Materials And Methods}

Study design: Purposive sampling.

Study population: 68 sandflies from houses of Kalaazar affected patients.

Study area: FulBaria Upazilla of Mymensing District.
Data collection tool: By questionaire.

Data Analysis: By Spss.

DNA extraction from sandfly was done by standard procedure using ATL buffer.

Primers used in this study:

K upper primer 5' GGG ATT GGA CTT GGT GGA 3'

K lowers primer 5' CAC AGC CCG CAG ATA CAA AT 3'

PCR Reactions: A four hundred and ninety eight$354 \mathrm{bp}$ fragment of DNA was amplified. PCR amplification was carried out in a $25 \mu \mathrm{m}$ of each dNTP, 10 pMols of each primer, and 1.25 unit of taq DNA polymarse enzyme. Samples were subjected to initial denaturation at $940 \mathrm{C}$ for 10 minutes followed by 35 cycles of $940 \mathrm{C}$ for $45 \mathrm{sec}, 550 \mathrm{C}$ for $30 \mathrm{sec}$ and 720 $\mathrm{C}$ for $1 \mathrm{~min}$ and $30 \mathrm{sec}$. Followed by final extension at $720 \mathrm{C}$ for $10 \mathrm{~min}$.

Electrophoresis: A gel was prepared with 1.5-\% agarose. After Amplification 10 $\mu$ samples of the PCR products and loading buffer was mixed and loaded into each well after electrophoresis the bands were stained with ethidiumbromide and the bands were analyzed and compared to the bands obtained with a positive leishmania DNA control. The bands obtained at $354 \mathrm{bp}$ are identical with bands, which were shown at 354 bp and sequenced by Shasuzzamans, et al., (2000).

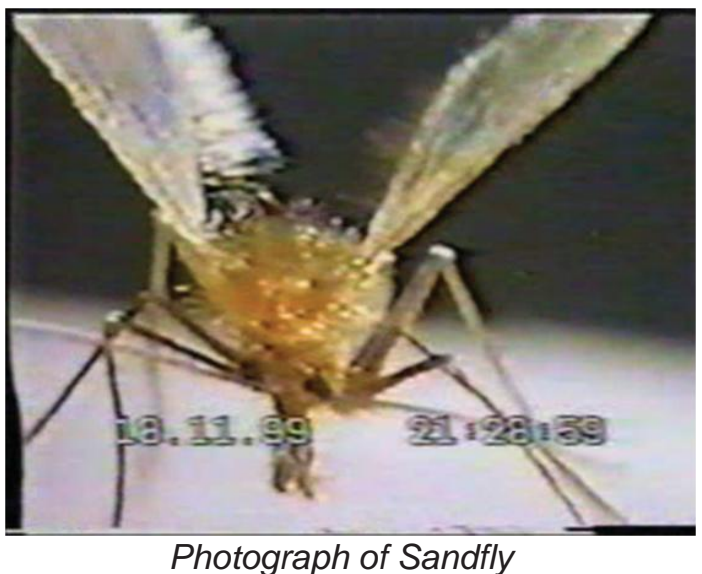

\section{Results}

Sand fly examination: An attempted was made to extract DNA from the sand fly, which were caught from the houses of Kala-azar affected patients. In one extraction 10 sand flies were used. After doing PCR similar bands were detected from the DNA extracted from this sand fly. Which indicates some of the sand fly in this extraction procedure were positive for promastigote. Several workers also tired before to find promastigote in sand fly by other technique. But 
we have extracted DNA from the sand fly and subsequent PCR showed this sand fly were having promastigote. Table-I, shows the pattern of sand fly caught from the dwelling of kala-azar patient. In the study DNA of promastigote were found from P. argentipes but not found in S. babu and S. sorti.

Table-I: Types of sand tly tound in the dwelling of kala-azar patient $(\mathrm{n}=68)$

\begin{tabular}{ccccc}
\hline Name & Male & Female & Total & $\%$ \\
\hline P. argentipes & 18 & 31 & 49 & 72 \\
S. babu & 6 & 6 & 12 & 18 \\
S. sorti & 1 & 6 & 07 & 10 \\
\hline Total & $\mathbf{1 5}$ & $\mathbf{5 3}$ & $\mathbf{6 8}$ & $\mathbf{1 0 0}$ \\
\hline
\end{tabular}

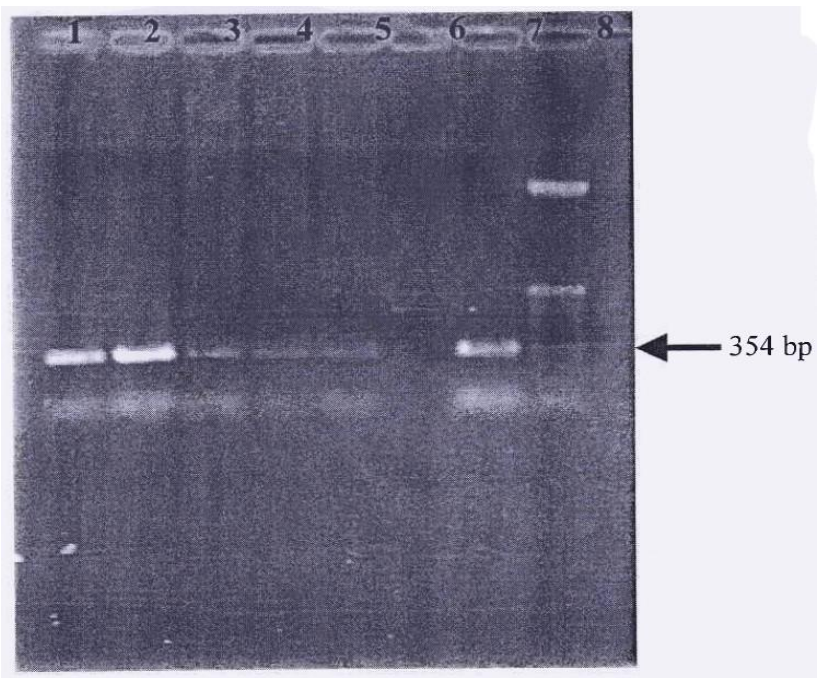

Fig -I: 354 bp Lane, 1 - Sand fly, 2 - Sand fly, 3 Buffy coat, 4 - Buffy coat, 5 - Bone marrow, 6 Negative control, 7 - Promastigote (Positive control), 8 - ladder.

\section{Discussion}

The success of vector control programs depends on the vectorial capacity and the understanding of disease transmission by the various vectors. We observed a P. argentipes \& phelabotoa as the most common genus follwed by Sergentomyia. In Bangladesh, other studies have also done of the distribution of sand flies, but in different endemic regions of Bihar state $^{8}$. The prevalence of $L$. donovani infection in the female P. argentipes population in Bangladesh has not been studied previously, although the Presence of
Leishmania DNA in Phlebotomus and Sergentomyia sand flies has previously been reported ${ }^{9}$. In this study a species-specific primer-based diagnostic PCR was used to detect parasitic nucleic acids in sand flied ${ }^{10}$. Another advantage of PCR is that this technique is highly specific and reproducible due to the use of specific and reproducible due to the use of specific primers for conserved regions of P. argentipes and $L$. donovani, whereas in microscopic dissection studies, there is the possibility of an observer mistaking for other flagellated parasites for $\mathrm{L}$. donovani ${ }^{11}$. In recent years, different methods have been developed to screen pools or clusters of insects, which can efficiently estimate the infection potential of disease spread by a vector species ${ }^{12,13,14,15}$. The rates of sand fly infection varied in accordance with the transmission of the disease, as observed in other studies reported from Panama ${ }^{16,17}$. The prevalence of infection with Leishmania in the the vector female $\mathrm{P}$. argentipes may be exploited as a tool for the surveillance of these infections and for measuring the success of control programs. To the best of our knowledge, this is the first report of a molecu- larbased study in a VL-endemic region of Bangladesh. Because of the lack of firm evidence and supporting literature regarding the prevalence of infection of sand flies in VL-endemic areas of Bangladesh, we expected that the prevalence of infection in these sand flies would be low. Large numbers of insects were examined to obtain an accurate estimate of infection levels. The high infection rates observed in this study indicate that a similar type of study can be performed on individual sand flies, which could provide vital information about vector control strategies to help control strategies to help control or eliminate VL in the Bangladesh.

\section{Recommendation:}

Community should be involve in sandfly control through the Primary Health Care approach. Cracks and cervices in the floor and walls of mud house should be repaired, cattle shade should be away from the living room.

\section{References:}

1. Birely H. Ann Trop. Med, and Parasitol 1993;87(4):319-334

2. Rahman KM, Islam N. Resurgence of visceral leishmaniasis in Bangladesh

3. Chowdhury S, Begum N et al. Report on sero epidemiology and chemotherapy of Kala azar in Bangladesh 1998; 
UNDP/WHO document.

4. Anderson KS, Gasim AM, Elhassan EAG, Khalii DC et al, Diagnosis of visceral leishmaniasis by the polymerase chain reaction using blood, bone marrow and lymph node samples from patients from patients from Sudan. Tropical Medicine International Health 1997;2:440-444.

5. Nuzum E, White IIIF, Thakur C, Dietze R et al. Diagnosis of symptomatic visceral leishmaniasis by use of polymerase chain reaction on patient blood. $J$ Infee Dis 1995; $171: 751-754$

6. Alam MJ, Rahman KM, Asna SMZH et al. Comparative studies on IFAT, ELISA and DAT for sero diagnosis of visceral leishmaniasis in Bangladesh. Band, Med, Res, Coun, Bull, 1996;22(1):27-32

7. Muazzam N. Comparative studies on some serological tests for diagnosis of visceral leishmaniasis in Bangladesh. 1990(M. Phil Thesis) microbiology, IPGMR, Dhaka.

8. Kumar V. Kesari S. Kumar AJ, et al. Vector density and the control of Kala-azar in Bihar, India. Mem Inst Oswaldo Cruz. 2009;104:1019-1022. [PubMed]

9. Mukherjee S. Hassan MQ. Ghosh A, et al. Short report: Leishmania DNA in Phlebotomus and WHO Bull 1983:61:113-116 Am J Trop Med Hyg. 1997;57:423-425. [PubMed]

10. Deborggraeve S. Boelaert M. Rijal S, et al. Diagnostic accuracy of a new Leishmania PCR for clinical visceral leishmaniasis in Nepal and its role in diagnosis of disease. Trop Med Int Health. 2008;13:1378-1383. [PubMed]

11. Srivastava P. Prajapati V. vanaerschot M, et al. Detection of Leptomonas sp. Prastites in clinical isolates of kalaazar patients from India. Infect Genet Evol. 2010;10:11451150.

12. Yameogo L. Toe L. Hougard JM, et al. Pool screen polymerase chain reaction for estimating the prevalence of Onchocerca volvulus infection in Simulium damnosum sensu lato: results of a field trial in an area subject to successful vector control. Am j Trop Med Hyg. 1999;60:124-128. [PubMed]

13. Martin-Sanchez J. Gallego M. Baron S, et al. Pool screen PCR for estimating the prevalence of Leishmania infantum infection in sandflies (Diptera: Nematocera, Phlebotomidae) Trans $\mathrm{R}$ Soc Trop Med hyg. 2006;100:527-532. [PubMed]

14. Bhattarai NR. Das ML. Rijal S, et al. Natural infection of Phlebotomus argentipes with Leishmania and other trypanosomatids in visceral leishmaniasis endemic region of
Nepal. Trans R Soc Trop Med Hyg. 2009;103:1087-1092. [PubMed]

15. Severinsson K. Jaenson TG. Pettersson J, et al. Detection and prevalence of Anaplasma phagocytophilum and Rickettsia Helvetica in Ixodes ricinus ticks in seven study areas in Sweden. Parasit Vectors. 2010;3:66. [PMC free article][PubMed]

16. Azpurua J. De La Cruz D. Valderama A, et al. Lutzomyia sand fly diversity and rates of infection by Wolbachia and an exotic Leishmania species on Barro Colorado Island, Panama,. PLoS Negl Trop Dis. 2010;4;e627. [PMC free article][PubMed]

17. Svododova M. Alten B. Zidkova L, et al. Cutaneous Leihmaniasis caused by Leishmania infantum transmitted by Phlebotomus tobbi. Int J Parasitol. 2009;39:251-256. [PubMed] 